\title{
دور التعليم الجامعي الإسلامي في إعداد الموارد البشرية القيادية للأمة الإسلامية
}

\section{خيران محمد عارف}

جامعة الإسلامية الثافعية، بإندونيسيا

khairanarif@gmail.com

\section{ملخّص}

يعتبر الاهتمام بالتعليم الجحامعى أحد المظاهر المهمة للنهضة والتقدم، باعتبار أن هذا النوع من

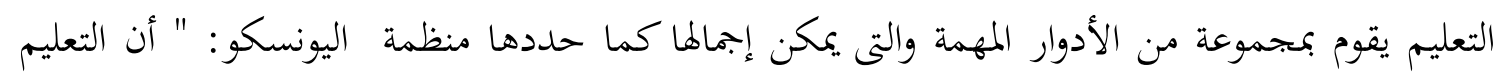

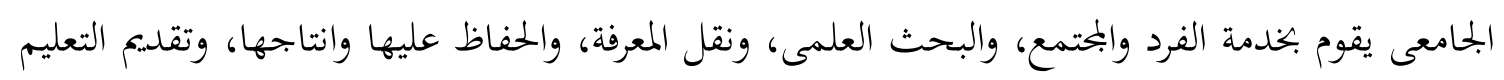
(1)" (1) (المستمر

وفى تاريخ الإسلام كانت الجامعات من مؤسسات التربوية الهامة فن إنتاج الشخصية القيادية

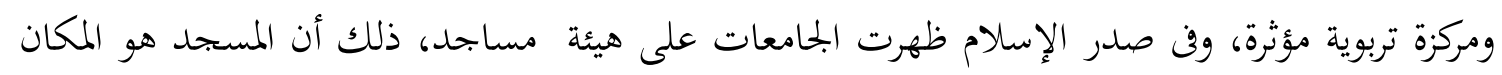

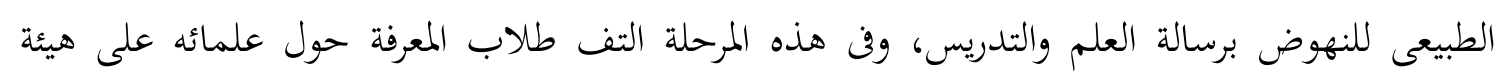

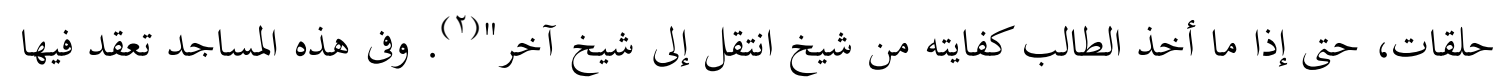

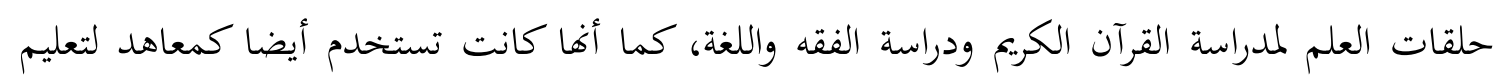

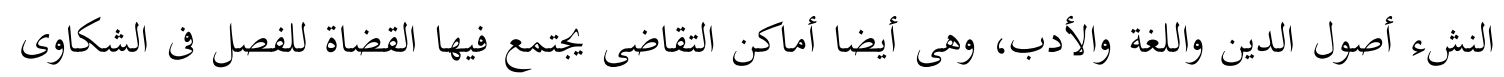

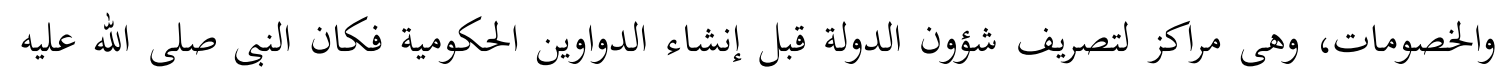

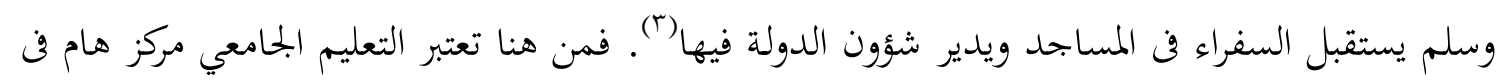
إعداد الموارد البشرية عبر العصور والأزمنة.

(1). UNESCO, World Conference on Higher Education, Higher Education In the Twenty First Century, Paris: $0_{-} 9$ oct. 1991, (PDF), Unesco.org, Online: $r \cdot / Y / Y$. Y Y,P. 1 1 1 -10

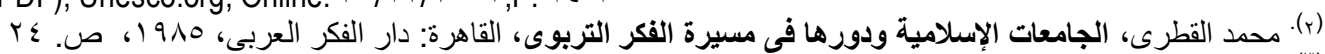

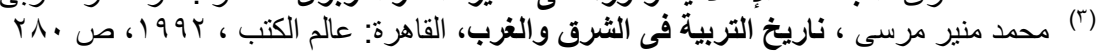




\section{أ. مفهوم الجامعة ووظائفها}

إن المصطلح جامعة مأخوذ من كلمة UNIVERSITY "الجامعة" وتعنى بها المؤسسة التى تعقد فيها

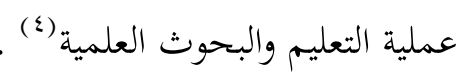

ويرى حامد عمار أن مصطلح "الجامعة" يعنى أكثر من تجمع الأساتذة، "فهو يتضمن أبعادا عديدة منها جامعة لمعارف عامة مشتركة تمثل قاعدة للمهن المتخصصة، وجامعة لمختلف إبداعات الفكر الإنسانى، وجامعة لثوابت المحتمع وخصوصياته الثقافية، وجامعة لموارد ومصادر المعرفة، بما ييسر بتحيدها وإنتاجها، وجامعة لفرق عمل متكاملة ومتعاونة، تتآلف مدارسهم الفكرية لخدمة الطلاب والارتقاء بالبحث العلمى وخدمة البحتمع" (0). إذن فالجامعة هى مكان التجمع المعلمين والمتعلمين أو الأساتذة والباحثين والطلاب، الذين يعملون على إنتاج العلوم والمعرفة والتكنولوجيا من خلال التدريس والبحث العلمى وخدمة البحتمع بالتجربة والخبرة، كما أكد ذلك بعض الخبراء في التعليم الجحامعى أن الجامعة هى "بحموعة من الأساتذة والباحثين والطلاب النابهين الذين ينصرفون إلى الدراسة والبحث والنظر والتأمل في جو من الجحل والمناقشة واستطلاع الآراء ومقاومة الحجج والتحصيل بالتجربة والخبرة"(?).

رأى البعض أن الجامعات لم يقصد بها - فن العصور الوسطى - المكان أو البيئة العلمية التى يلتقى فيها رجال العلم من معلمين ومتعلمين وإنما قصد بها الاتحاد الذى يكونه كل فريق من هذين الفريقين لرعاية مصالحه وتنظيم أموره. وأما المكان أو البيئة العلمية التى نطلق عليها اليوم باسم "جامعة " "فقد أطلق عليها في أوربا العصور الوسطى اسم "المدرسة العامة" بمعنى المكان الذى يستقبل طلاب العلم الوافدين من جميع الجهات لا لا لإنى

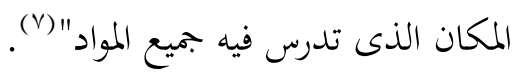

وفى صدر الإسلام فإن المسلمين وإن كانوا لم يستخدموا مصطلح الجحامعة طوال العصور الوسطى، فإن معظم المدارس غدت جامعة بالمعنى الحديث الذى نعرفه، سواء من ناحية تنوع الدراسات التخصصية، ورقى مستواها فيها أو في قدرتا على استيعاب طلاب العلم الوافدين إليها من شتى الأمصار (^).

ومن ثم فقد أخطأ البعض حين قالوا أن في العصور الوسطى قد عرف الناس كلمة "الجامعة" بمعناها التجمع العلمي الذى يضم فيه الطالب والمعلم كما نعرفها اليوم، "بل إن لفظ جامعة تحور عند فاية القرن الثانى عشر الميلادي وبداية القرن الثالث عشر الميلادى حتى أصبح يطلق على اتحادات المشتغلين بالعلم والتعلم من

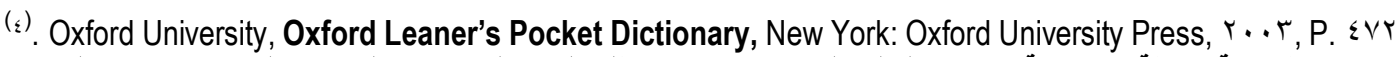
(ه) حامد عمار , الجامعة رسالة ومؤسسة, مؤتمر التعليم العربى وتحديات مطلع القرن الحادى والعشرين الكويت : جامعة الكويت, ro ص , 199

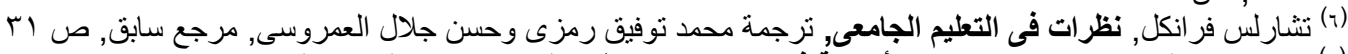

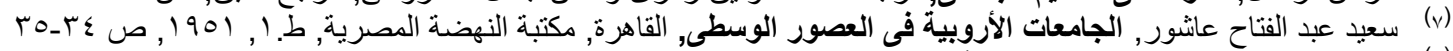

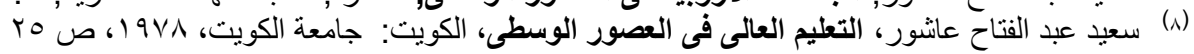




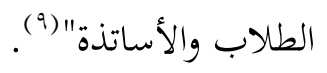

فالتعليم الجامعى في العالم الغربى -بالمفهوم الذى يضم فيه الإتحاد الأساتذة والطلاب- ظهر في بداية القرن الثالث عشر الميلادى كما أكد ذلك بعض المؤرخين فن التعليم الجحامعى "أن الجحامعات قد نشأت على الألى أهاد

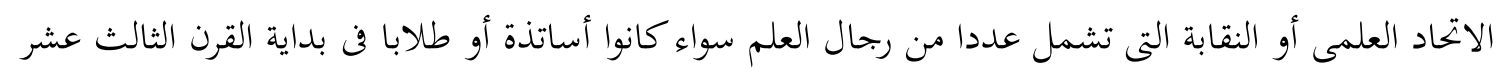

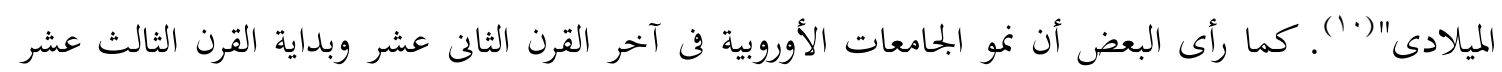
وكانت الدراسة فن هذه الجامعات تتركز في زيادة المعرفة من ناحية وتشجيع الأباطرة والرؤساء الدينيين والملوك والمختمعات المحلية من ناحية أخرى (11). ومن أمثلة الجامعات التى ظهرت فن العصور الوسطى

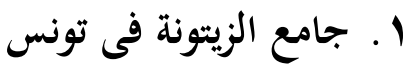

يمثل جـامع الزيتونـة معهـد التعليم العـالى بتونس في العصـور الوسطى، بنـاه الوالى عبــ الله بـن

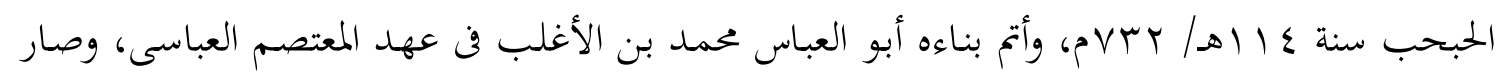
من أهم مراكز الثقافة الإسلامية على عهد أبى زكريا الأول، في أوائل القرن السابع الهجرى(rII). كـان جـامع الزيتونـة كـالجوامع الإسـلامية الكـبرى في العـالم الإسـلامى، إذ تمثلـت فيـه الأنشطة المختلفة، فهو مسجد لإقامة الصلاة، ومكان يتجمع فيه المسلمون للتعارف وإقامة الحفلات الدينية. ومن أهم هذه الأنشطة "قيام جامع الزيتونة كمعهد علمي، يتلقى فيه المسلمون تعاليم الإسلام، وتفسير القرآن، وأحاديث الرسول صلى الله عليه وسلم، على كبار التابعين والمحتهدين، ممن تلقوا العلم على كبار الصحابة

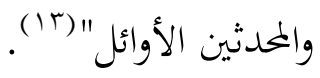

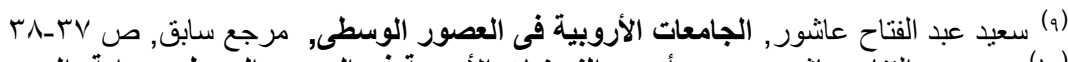

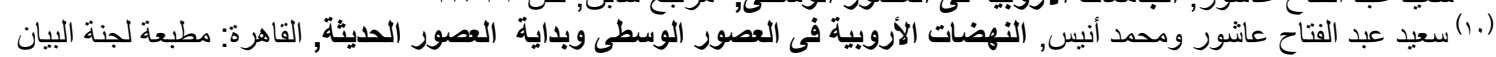

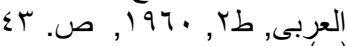

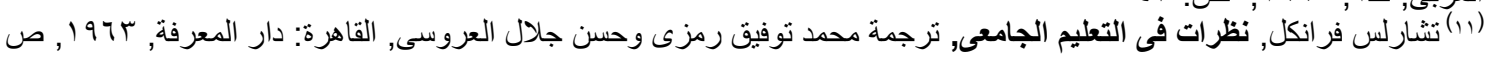
(r, (r) محمد القطرى، الجامعات الإسلامية ودورها فى مسيرة الفكر التربوى، مرجع سابق ص. 10 9 ( 
ومن هنا أصبح "جامع الزيتونة جامعة حقا، وازدهر فيها التعليم فن عهد الحفصيين في أوائل القرن السابع/الثالث عشر الميلادى، إذ جلب إليه أبو زكريا الأول -الحاكم الحفصى - الأساتذة مـ الأندلس وصقلية لتدريس الفقه واللغة والأدب والتاريخ والفلسفة والرياضيات والطب" (ع ().

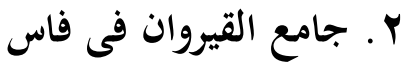

ومسن أشهر الجوامسع فن الإسـلام الذى قام بدراسة العلوم الدينية والعقليـة في العصسور الوسطى، جـامع القـيروان في فـاس، "وكان مـن أهـم المسـاجد الجامعة فى بـاد المغرب وأكثرهـا شهرة لكونه جامعة إسـلامية عريقـة ضـاربة بجـذورها في أعمـاق التـاريخ، وكانـت هـذه الجامعـة تقـارع الأزهـر الشـيف في العلم وتخريج الدعاة والعلمـاء والفقهاء"(1) . ولقـد مـر جـامع القيروان بثلاثنة أدوار: "الأول عند تأسيسه عـام

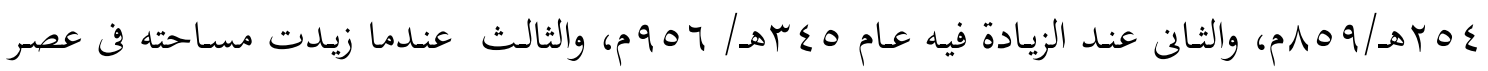
على بن يوسف سنة • roهـ/هr ا ام، وتولى مشروع زيادة مسجد القيروان وتوسيعه القاضى أبو عبد الله محمد بن داود بسسب ضيق المسجد بالناس" (7 ( ).

وبعد توسعته أصبح جامع القيروان مركزا مهما للثقافة الإسلامية، بل أصبح المركز الرئيسى للتعليم العالى في المغرب، وكان الهدف الدينى هو الهدف الرئيسى من الدراسة فن جامع القيروان، كماكانت عليه الحال في المساجد الإسلامية الأخرى في تلك العصور. "وفى إطار هذا الهدف الدينى برزت أهداف أخرى سياسية واقتصادية واجتماعية، فبالرغم من أن العلوم الدينية كانت تحظى باهتمام كبير، لما لها من منزلة عالية فن نفوس المسـلمين، إلا أن الدراسة، لم تقتصر على هذه العلوم، بـل شنملت أيضـا الفلسفة والطب والصيدلية والطبيعة، والفلك والهندسة" (V) .

وأكد بعض المؤرخين في تاريخ الإسلام أن جامع القيروان أصبح "جامعة متقدمة في القرن الثالث الهجرى/التاسع الميلادى، شاهدا على ديمقراطية التعليم وعلى طرق التدريس ومراحل التعليم، وتخصيص كراسي الأستاذية، وشروط التعيين فن وظائف التدريس ومراسيم تعيينهم، ودرجاتقم العلمية، والإجازات

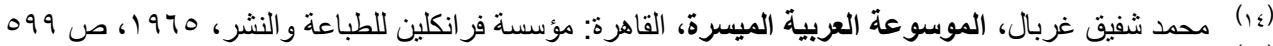

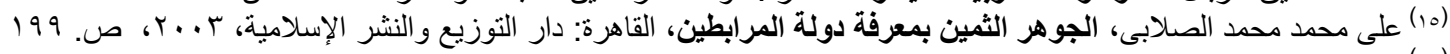

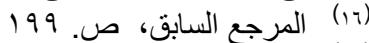

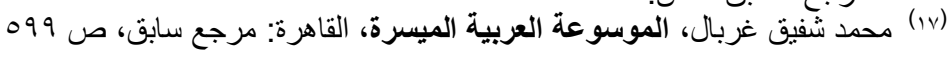


الفخرية، وبحالس أوصياء الكليات، والمساكن الجحامعية للأساتذة والطلاب، والمكتبات الجامعية. وفى هذه الجحامعة الإسلامية وضع أساس التقاليد الجامعية التى تسير عليها الجحامعات في الأمم الراقية، كحفلة افتتاح الدراسة، وحفلة التخرج، واتحاد الطلبة، وغير ذلك مما يدل على أن المسلمين سبقوا الأوروبيين فن ديمقراطية

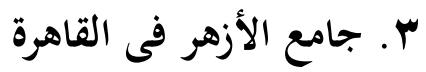

أنشأ الجامع الأزهر جوهر الصقلى، قائد الخليفة المعز لدين الله الفاطمى، إذ شرع في بنائه في ع جمادى الأولى سـنة وه هـ / • V9م، وتم بناؤه في سنتين تقريبا وأقيمت الصلاة فيه فن V رمضـان عـام

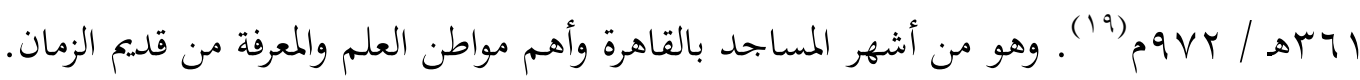

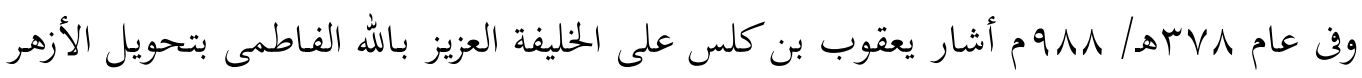
إلى جامعة أو معهد للدراسة المنظمـة، تـدرس فيها العلوم الدينية والعقلية، وعمل الخلفـاء الفـاطميون مـن

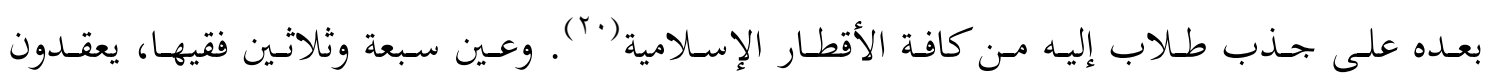
بحالسهم بالأزهر في كل يوم جمعة بعد الصلاة حتى العصر (Ir). وكان هؤلاء الفقهاء أول الأساتدة المدرسين الذين عينوا بالأزهر، ومن هذا التاريخ بدأ الأزهر يكتسب صفته العلمية الحقيقية كمعهد للدراسة المنظمة، وحياته الجامعية التى امتدت عبر القرون (r؟). أما المحتوى التعليمى الذى ساد في التعليم الأزهرى في هذه الفـترة يتكون مـن العلوم الدينيـة واللغويـة، والعلوم العقلية. فتشـتمل العلوم الدينيـة واللغويـة على التفسير وعلومه، والحديث وعلومه، والفقه وأصوله، وقواعد اللغة من النحو والصرف، وغيرها، حيث ذكر المقريزى أنه "عامر بتلاوة القرآن ودراسته وتلقينه والاشتغال بأنواع العلوم والفقه والحلديث والتفسير والنحو وبحالس الوعظ" ("זr). وتشمل العلوم العقلية على الفلسفة والمنطق والطب، والرياضيات وغيرها كما أكد ذلك بعض

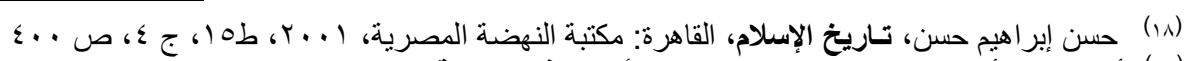

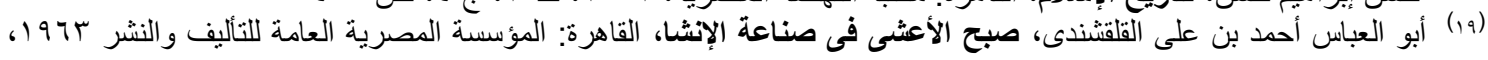

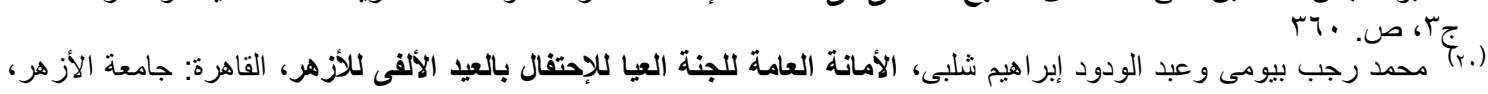

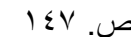

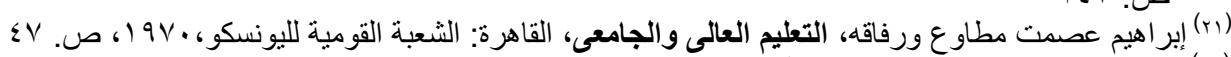

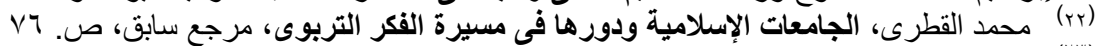
(Tr) 
المؤرخين، "أن الأزهر قد أخذ بنصيب من العلوم العقلية أيضا، منذ ضعف شأن دار الحكمة في بغداد، فدرست به علوم الفلسفة والمنطق والطب والرياضيات" (عَ).

هكذا تحـول الجـامع الأزهـر مـن جـامع إلى دراسـة جامعيـة منظمـة منـذ عـام

ودرسـت فيها العلوم المختلفـة مـن العلوم الدينية واللغوية والعقليـة معا "مـا جعل الأزهر أقـدم جامعـة في العالم"(هr). وظل الأزهر فلك العلوم الدينية واللغوية وبعض العلوم العقلية، حتى تم التطوير العظيم في حياة هذه الجامعة الإسلامية الكبرى على يد الثورة المصرية في عام الب 9 ام (Tr). هكذا كانت نشأة الجامعات الإسلامية في صدر الإسلام في العصور الوسطى بدأت نشأقةا من المساجد والمدارس التى تمارس العملية التعليمية من محتوى العلوم المختلفة، ثم أصبحت جامعات كبرى فن تلك الفترة، تخرج منها كثير من العلماء والمفكرين والمثقفين في العالم الإسلامى بل فن العالم الغرب، كما كانت هناك مساجد أخرى قامت بوظيفة الجامعات في هذه الفترة كأمثال الجامع القرطبى في الأندلس، والجحامع الأموى وغيرها فن العالم العربى والإسلامى ومنها مساجد فن إندونيسيا، والتى أصبحت على غرار الجامعات الإسلامية عبر العصور.

في العالم الغربى هناك روائد الجحامعات الحميثة منها: "جامعة سالرنو في القرن الثانى عشر الميلادى والتى

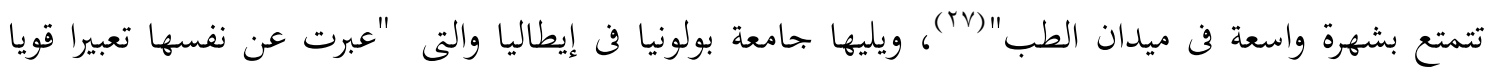

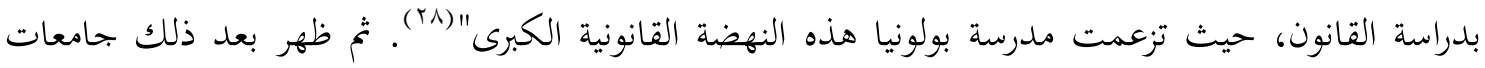

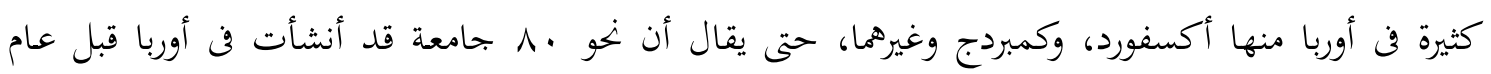

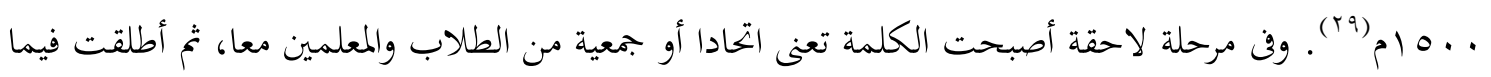
بعد لتعنى المعهد العلمى الذى يستخدم أساتذة ويعلم طلابا(·r).

فالجامعة بها كليات تدرس فيها علوم متعددة ومهارات مختلفة. فقد رأى البعض أن الكلمة "كلية" "مأخوذة من الكلمة اللاتينية COLEGIO وتعنى "القراءة معا"، وقد استخدم الرومان الكلمة في القرن الثانى

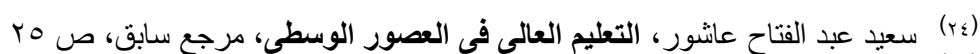

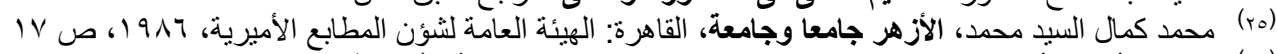

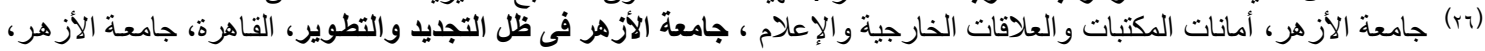
$1 \%-1 \cdot 19 \vee 9$

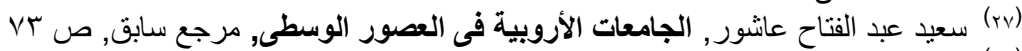

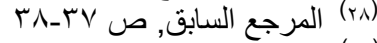

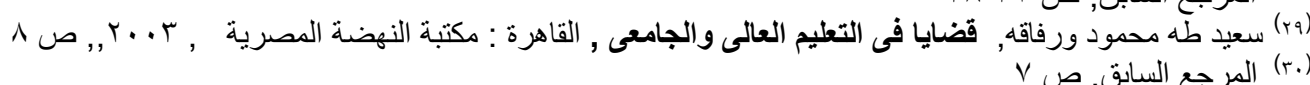


عشر لتدل على بحموعات من الحرفيين والتجار، ثم استخدمت الكلمة "كلية" يعنى COLLEGE في أكسفورد

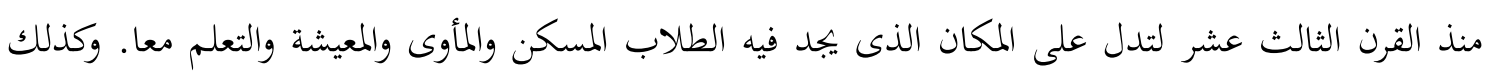
كلمة "كلية" FACULTY فهى مأخوذة عن الكلمة اللاتنية وتعنى القوة أو القدرة" (اr).

يتضح من التعريف السابق للجامعة أن الوظائف الأساسية للجامعة متمثلة في التدريس والبحث العلمى وخدمة المحتمع، كما أكد ذلك منظمة اليونسكو "أن وظائف الجامعات ومهامها الأساسية تتركز على ثلاثة وظائف هى: التعليم والبحث والخدمات" (rr).

أما التعليم الجحامعى اليوم فهو التعليم الجحامعى الحكومى وغير الحكومى ، الذى يلى المرحلة الثانوية ، أو

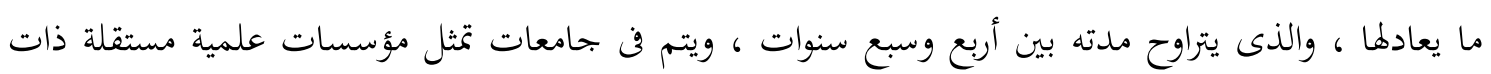
هيكل تنظيمى معين ، وأنظمة وأعراف وتقاليد جامعية معينة ، وتتألف الجامعة من بمحموعة من الكليات والفي والأقسام

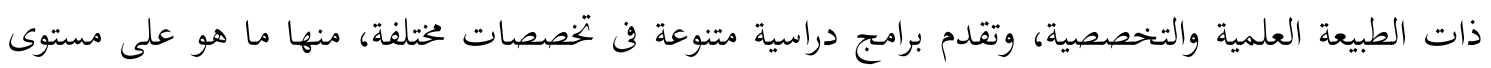
البكالريوس أو الليسانس، ومنها ما هو على مستوى الدراسات العليا، كالدبلوم العالى والماجستير والدكتوراه، وتمنح

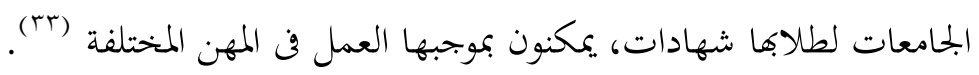

هكذا مفهوم الجامعة وكوها مؤسسة تعليمية عالية في البمتمعات، وقد كانت مفهومها بداية نشأهما في

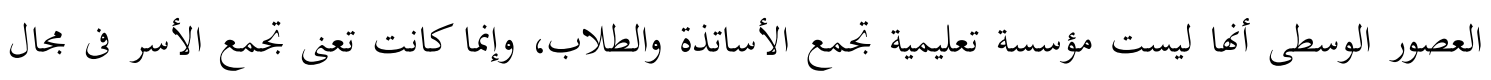
السياسة وممارسة السلطة، تم أطلقت فيما بعد لتعنى المعهد العلمى الذى يستخدم أساتذة ويعلم طلابا كما عرفنا اليوم، حيث تنقسم إلى حكومى وغير حكومى، وتتم الدراسة فيها بعد مرحلة الثانوية، أو ما يعادلها، والتى تتراوح مدتا بين أربع وسبع سنوات، وتتكون من الكليات والأقسام ذات الطبيعة العلمية والتخصصية، وتقدم برامج دراسية متنوعة كالبكالريوس أو الليسانس، والدبلوم العالى والماجستير والدكتوراه، وتسعى إلى تنفيذ وظائفها

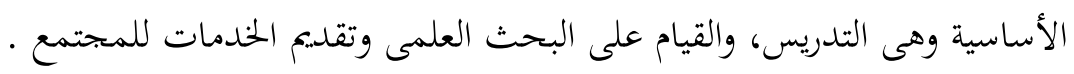

\section{ب. الجامعات وتحدياتها في إعداد الموارد البشرية}

فقد واجهت الجامعات اليوم العديد من المعوقات والتحديات التى قد تقف حائلا أمامها في القيام بمسؤليتها ومنها زيادة الطلب على التعليم الجامعى، وقلة الموارد المالية للتوسع فيه وبتحيده، والحاجة إلى رفع مستوى الجودة سواء فن النواحى الإدارية أو الأكاديمية والذى له أكبر الأثر على مستوى الخريج ورفع كفائته

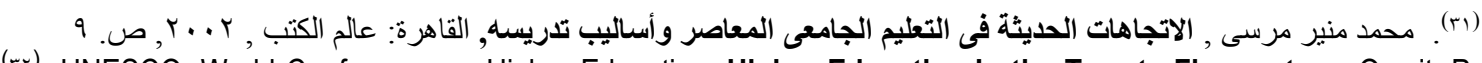
(rr). UNESCO, World Conference on Higher Education, Higher Education In the Twenty Firs century, Op.cit, P. r.

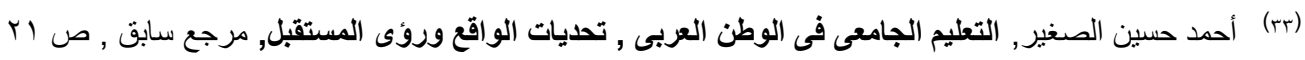


(عَr) كما واجهت هذه الجامعات تحديات جسام من العولمة وتكنولوجيا المعلومات والإتصالات، وقوانين اقتصاد السوق(ro)، والثورة العلمية والإبحازات التقنية غير المسبوقة، والثروة الهائلة في بحالات الاتصال والإلكترونات، والنظام العالمى الجمديد، والتكتلات الاقتصادية العملاقة، والتغير المعرفى والتغير الديموغرافن

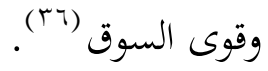

وفى مقدمة هذه التحديات تحديات بحتمع المعرفة الذى يؤكد أن المعرفة قوة، وهو بحتمع يقوم على

أساس إنتاج المعارف، الأمر الذى يؤكد أن بحرد اكتساب المعلومات والدراسة عنها، واستخدام التقنيات المعاصرة، كأداة تيسر الحصول على المعلومات ليس كافيا، وإنما لا بد من بتحاوز ذلك إلى عمليات إنتاج حقيقية للمعارف، ولايتأتى ذلك إلا من خلال الترابط الوثيق بين العلم والتكنولوجيا والبحتمع (rV).

فالجامعات في الدول النامية تواجه قضايا تدنى مستوى خريجها بمعنى أن بعض مخرجات هذا

التعليم ليست على المستوى المطلوب، أو بالمواصفات التى يتطلبها سوق العمل، الأمر الذى يؤدى إلى احجام المنظمات والمؤسسات المختلفة عن تعيين خريجي التعليم العالى والجحامعى في هذه الدول النامية محا يؤدى بدوره إلى انتشار البطالة وتفاقم المشكلات في المحتمع. وعلى سبيل المثال لقضايا تدلى مستوى خريج الجحامعات في إندونيسيا الذين لا يجدون فرصا للعمل (البطالة المتعلمة) من خريجي التعليم العالى في إندونيسيا ومن ضمنه الجامعات الإسلامية، حيث تزداد عددهم من عام إلى عام ويتراوح الزيادة بين هـ إلى · إمل عام ^ب كما بينها الجدول الآتي:

تطور عدد خريجي التعليم العالى والجحامعى فن إندونيسيا الذين لم يجدوا فرصا للعمل بين عامى ... بام-

$$
\text { :pr..V }
$$

${ }^{\left(r_{\varepsilon}\right)}$. Association of University Teachers, Higher Education, preparing for the $r$ /st century. U.K : Spiring $1990, P$. 0

(ro). Robert Switzer, Does the University Have a future, Virtual Learning, the market model and Education in Egypt: a Millennial Assesment, The American University in Cairo, proceedings of the vth AUC Research Conference, Cairo, $Y \cdots$, P. $Y \varepsilon$

(rr). James J. Duderstail, The Future of Higher Education, New Roles for the $r$ st Century University .U.K winter, 1999, P. Y,, r

(rv). Pinch, Steven, Knowledge Communities, Special Theory and Social Policy, Social Policy and Administration, vol. rr, No. 0,1991

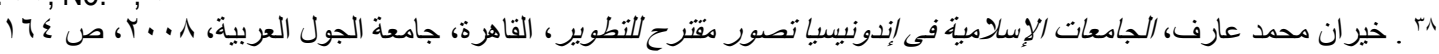




\begin{tabular}{|c|c|c|c|}
\hline الإجمالى & الإناث & الذكور & عام \\
\hline rVч.... & $1 \leqslant \uparrow \ldots .$. & 1 row... & r... \\
\hline r८१.... & $1 \leqslant r \ldots$ & $1 \leqslant 7 \ldots$ & $r \ldots r$ \\
\hline$r 79 . .$. & 1ro.... & Iro.... & $r \ldots r$ \\
\hline$r \leqslant 0 . .$. & 1 1 ז.... & $1.9 . \ldots$ & $r \ldots r$ \\
\hline$r \varepsilon \wedge . .$. & $191 . \ldots$ & $10 . \ldots$ & $ץ \ldots \varepsilon$ \\
\hline 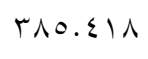 & $r \ldots .9 r 1$ & $1 \leqslant \wedge . \leqslant 9 \vee$ & r... \\
\hline$r v 0.7 .1$ & $1117 . .49$ & $119.0 \mathrm{VT}$ & $r \ldots q$ \\
\hline$\varepsilon .9 . \wedge 9$. & rTr. & $189.00 \mathrm{~V}$ & $r \cdots v$ \\
\hline
\end{tabular}

Source: Dinas Tenaga Kerja dan Transmigrasi، Jumlah Pengangguran Menurut Pendidikan tahun $r \cdots$. , www.naketrans.go.id، Online: $\uparrow \wedge$ oktober $r . . \vee$

$$
\text { يتضج من العرض السابق ما يلى: }
$$

1- أن ارتفاع نسبة خرجي الجامعات فن إندونيسيا الذين لم يجدوا فرصا للعمل تتراوح بين ه\%-

$$
\text { \% }
$$

r- إن ارتفاع نسبة الملتحقين بالجامعات الإسلامية وارتفاع نسبة خريجها الذين لا يجدون فرصا للعمل يدل على أن الأهداف والمناهج الدراسية في هذه الجامعات منفصلة عن متطلبات سوق العمل، وغاب عنها التنسيق والتخطيط مع سوق العمل، ومن ثم أصبحت وظيفة "الموظف الحكومى" في المؤسسات الحكومية، الخيار الوحيد لخرجي الجامعات. 
